Available online at https://jurnal.stmikroyal.ac.id/index.php/jurdimas

\title{
PELATIHAN BLOG SEBAGAI SARANA PUBLIKASI PEMBELAJARAN GURU SMA NEGERI 2 KISARAN
}

\author{
Guntur Maha Putra $^{{ }^{*}}$, Novica Irawati ${ }^{1}$, Adi Prijuna ${ }^{2}$ \\ ${ }^{1}$ Sistem Informasi, STMIK Royal Kisaran \\ ${ }^{2}$ Sistem Komputer, STMIK Royal Kisaran \\ email:*igoenputra@gmail.com
}

\begin{abstract}
As a formal education institution, acculturation of techniques in Teaching and Learning Activities (KBM) is required by each lesson teacher to be able to transfer knowledge to students maximal and optimally. So far the teaching carried out by the teachers of SMA 2 Kisaran is more dominant in learning done face-to-face in the classroom, so that learning requires the mind and energy that is extra because it is done repeatedly in the classroom and the hours that different. Starting from the above, the dedication team sought solutions so that teaching can be acculturated by online learning using blog media to publish teachers' teaching materials to the internet. It is expected that online-based teaching techniques, one of which is outlined in the making and utilization of blogs can stimulate interest from students to access teaching materials that have been published online, both in the form of text, images, audio and learning videos that have been recorded and uploaded by the teacher into his blog whenever and wherever it is, so that it will create student centered learning and learning objectives can be achieved.
\end{abstract}

Keywords: blogs, teaching materials, online publications, videos, student center learning.

\begin{abstract}
Abstrak: Sebagai institusi pendidikan formal maka diperlukan akulturasi teknik dalam Kegiatan Belajar Mengajar (KBM) yang dilakukan oleh masing-masing guru pelajaran untuk dapat mentransfer ilmu pengetahuan kepada peserta didik secara maksimal dan optimal. Selama ini pengajaran yang dilakukan oleh guru-guru SMA Negeri 2 Kisaran lebih dominan kepembelajaran yang dilakukan secara tatap muka di dalam kelas, sehingga pembelajaran membutuhkan pikiran dan tenaga yang ekstra karena dilakukan secara berulang-ulang pada kelas dan jam yang berbeda. Berawal dari hal diatas maka tim pengabdian mencari solusi agar pengajaran dapat diakulturasi dengan pembelajaran secara online menggunakan media blog untuk mempublikasikan bahar ajar para guru ke internet. Diharapkan dengan teknik pengajaran berbasis online salah satunya yang dituangkan dalam pembuatan dan pemanfaatan blog dapat merangsang minat dari para siswa untuk mengakses bahan ajar yang telah dipublikasikan secara online baik informasi berupa text, gambar, audio maupun video pembelajaran yang telah direkam dan diupload oleh guru ke dalam blognya kapan dan dimanapun berada, sehingga akan tercipta pembelajaran berpusat pada siswa (Student Centred Learning) dan tujuan pembelajaran dapat tercapai.
\end{abstract}

Kata kunci: blog, bahan ajar, publikasi online, video, Student Center Learning. 
Available online at https://jurnal.stmikroyal.ac.id/index.php/jurdimas

\section{PENDAHULUAN}

SMA Negeri 2 Kisaran yang beralamat pada jalan Latsitarda Nusantara VII , Kecamatan Kisaran Naga Kabupaten Asahan Sumatera Utara merupakan salah satu institusi pendidikan favorit dan terkemuka di Asahan. Pada sekolah ini banyak dihasilkan lulusanlulusan yang berprestasi baik di tingkat lokal maupun tingkat nasional. Pada saat ini SMA Negeri 2 Kisaran dipimpin oleh Bapak Syahruddin Lubis, S.Pd., MM.

Guru-guru di SMA Negeri 2 Kisaran hampir rata-rata memiliki fasilitas berupa laptop untuk mendukung proses pembelajaran mereka, tetapi masih sebatas dalam penggunaan aplikasi microsoft office saja. Dari pengamatan tim ratarata para guru belum memanfaatkan teknologi informasi secara maksimal khususnya dalam pemanfaatan blog dalam pembelajarannya, padahal jika diperhatikan minat belajar baik dari guru yang senior maupun guru yang junior sangatlah tinggi untuk belajar mengenai teknologi informasi ini. Hal ini tercermin dari masukan untuk diadakannya pelatihan-pelatihan yang berhubungan dengan peningkatan IT para guru. Melihat belum maksimalnya penggunaan teknologi informasi para guru khususnya dalam penggunaan blog serta masukan dari kepala sekolah untuk mengangkat tema pelatihan mengenai blog, maka tim menyusun strategi untuk melakukan pelatihan pembuatan blog sebagai sarana publikasi pembelajaran guru-guru SMA Negeri 2 Kisaran.

\section{METODE}

Tahapan atau langkah-langkah yang ditempuh untuk kelancaran dan tercapainya tujuan kegiatan pengabdian kepada masyarakat ini adalah:

1. Memastikan tempat dan fasilitas pendukung seperti in focus, projector, koneksi internet dan lainnya sudah standby sebelum kegiatan akan dilangsungkan beberapa saat.

2. Memberikan modul yang berisi materi-materi kegiatan, menampilkan slide presentasi, dan alat peraga lainnya yang mendukung kegiatan pengabdian.

3. Memastikan komputer / laptop setiap peserta sudah terkoneksi ke internet.

4. Menjelaskan teori pengetahuan mengenai blog dan manfaatnya dalam dunia pendidikan.

5. Menjelaskan dan mempraktekkan cara pembuatan email dan manajemen account email, google drive, google class, youtube dan praktek publikasi (upload) bahan ajar pembelajaran baik berupa text, audio, gambar maupun video recording pembelajaran ke dalam blog masingmasing.

6. Diskusi dan tanya jawab mengenai permasalahan-permasalahan yang dihadapi peserta dalam kegiatan praktek pembuatan blog.

Dalam kegiatan ini kepala sekolah menyediakan tempat berupa aula dan fasilitas-fasilitas penunjang berupa $\mathrm{mi}$ crofon, sound system dan lainnya yang mereka punya untuk mendukung kegiatan ini berjalan dengan baik dan lancar sesuai harapan. Setelah kegiatan pengabdian kepada masyarakat dilakukan, maka langkah selanjutnya tim pengabdian kepada masyarakat melakukan tinjauan dan monitoring untuk memastikan peserta sudah memahami dan mempublikasikan bahan ajarnya ke dalam blognya masingmasing secara benar dan tersistematis. 
Available online at https://jurnal.stmikroyal.ac.id/index.php/jurdimas

Jika ada kendala tim bersedia membantu dengan melakukan pendampingan kembali.

\section{PEMBAHASAN}

A. Materi

Pembuatan Blog dengan Blogspot

1. Untuk memulai membuat blog dengan Blogger kita sudah harus memiliki email dari account google. Dalam tutorial ini email yang penulis gunakan adalah ithousemedia@gmail.com, kemudian kunjungi homepage dari blogger di alamat https://www.blogger.com. Masukkan username dan password email yang telah dibuat sebelumnya, lalu klik Masuk.

2. Pilih bahasa yang digunakan (Bahasa Indonesia), kemudian klik tombol Lanjutkan Ke Blogger.

3. Maka akan diteruskan ke link halaman

https://www.blogger.com/home, selanjutnya klik tombol Blog Baru untuk mulai membuat blog

4. Isikan judul yang mewakili judul blog kita misal IT_HouseMedia Blog, masukkan juga alamat dari blog kita contoh ithousemedia.blogspot.com dan pilih template/tampilan blog yang disukai. selanjutnya klik Buat blog! untuk proses buat blog.

5. Maka blog kita telah berhasil dibuat. Klik tanda gambar pinsil orange untuk mulai menulis (mengeposkan) artikel atau jika kita ingin melihat tampilan dari blog kita klik tombol Lihat blog.

Tentang Dashboard Blogspot

Kita dapat memilih option dashboard untuk melakukan pengaturan lebih lanjut. Atau mengklik icon Buka daftar entri untuk menuju ke link halaman dashboard blog kita secara keseluruhan.

1. Pada halaman dashboard tersebut berisi menu berupa ikon-ikon yang dapat digunakan untuk melakukan berbagai tindakan / pengaturan pada blog, seperti penjelasan dari menu berikut ini :

Ikhtisar : Berisi mengenai informasi ringkas mengenai aktivitas blog, penayangan statistik, pembaruan, berita dari blogger, panduan blogger dan informasi lainnya.

Entri baru : digunakan untuk mengakses editor post agar dapat menulis posting baru di blog kita. Caranya klik ikon pensil orange atau dengan mengklik tombol Entri baru. Klik Publikasikan untuk menerbitkan artikel ke halaman blog atau klik Simpan untuk menyimpan sebagai draft yang lain waktu dapat dipublikasikan.

Laman : Digunakan untuk membuat halaman statis dari blog kita yang linknya diambil dari tulisan yang kita posting.

Komentar : Berisi mengenai komentar-komentar yang masuk maupun spam.

Google+ : Berisi tentang setelan google+ dan cara-cara untuk meningkatkan blog kita dengan Google+.

Statistik : Berisi tentang perkembangan statistik dari blog kita berupa statistik dalam bentuk ikhtisar, pos, sumber lalu lintas maupun pemirsa / pengunjung.

Kampanye : Menu dengan upaya untuk mendatangkan pembaca baru atau membuat pembaca datang kembali ke blog kita, dalam hal ini fasilitas AdWords dapat digunakan untuk membantu meningkatkan keterliha- 
Available online at https://jurnal.stmikroyal.ac.id/index.php/jurdimas

$\tan$ blog kita.

Tata Letak : untuk menambah, menghapus, mengedit gadget di blog kita. Dapat digunakan dengan mengklik dan seret untuk menata ulang gadget di blog. Untuk mengubah kolom dan lebar, dapat menggunakan Desainer Template.

Template : digunakan untuk mengubahsuaikan template sesuai dengan keinginan baik berupa latar template blog, tata letak, warna , font dan lain-lain.

Setelan : berisi menu-menu setelan dasar, pos dan komentar, seluler dan email, bahasa dan pemformatan, preferensi penelusuran dan lainnya.

Menulis Posting di Blog

1. Masuk ke account blogger di https://www.blogger.com. Setelah masuk ke Blogger, klik ikon pensil oranye untuk mulai menulis posting baru, dan masukkan tulisan yang ingin kita tulis dan bagi dengan pengunjung.

2. Berikutnya, akan muncul halaman Posting Editor. Mulailah dengan memberikan judul pada posting blog kita (opsional - misal : Selamat Datang di IT_HouseMedia Blog), kemudian masukkan isi dari posting blog kita.

3. Kita dapat memberi pengubahan tindakan ataupun style pada isi blog kita dengan bantuan icon-icon yang tersedia berikut ini :

4. Setelah selesai, klik tombol Pratinjau di bagian atas untuk melihat hasil preview dari postingan kita, agar jika ada kesalahan dapat di edit kembali, atau kita juga dapat mengklik tombol Simpan untuk menyimpan isi posting kita sebagai draft yang sewaktuwaktu dapat kita edit/ubah kembali. Jika sudah selesai diedit klik tombol
Publikasikan untuk mempublikasikan isi postingan pada halaman blog kita. Selanjutnya kita dapat mengisi postingan lain dengan langkahlangkah yang sama pada penjelasan cara menulis posting di blog.

Menambah Gambar Pada Isi Blog

1. Untuk menambahkan gambar agar dapat disisipkan pada blog kita, caranya letakkan kursor di area yang ingin disisipkan gambar kemudian klik ikon gambar (Insert image) di toolbar Pos Editor.

2. Sebuah jendela akan muncul meminta kita untuk menelisik file gambar di komputer kita (Upload), atau kita dapat juga memasukkan gambar dari menu From this blog maupun Lainnya.

3. Klik tombol Pilih file untuk memilih gambar dari komputer kita (kita dapat mengunggah beberapa file gambar sekaligus, gunakan file JPG, GIF atau PNG), selanjutnya pilih gambar dan klik Add selected.

4. Setelah itu gambar akan disisipkan di area kursor yang kita letakkan sebelumnya, klik pada gambar agar dapat memilih pengaturan ukuran SmallMedium-Large-XLarge-Original size (Kecil-Sedang-Besar-Lebih BesarUkuran Asli), posisi gambar LeftCenter-Right (Kiri-Tengah-Kanan) untuk menentukan bagaimana gambar akan muncul di posting kita, juga dapat ditambahkan keterangan dari gambar (Add Caption), properti gambar (Properties) dan Remove jika ingin menghapus gambar tersebut.

5. Pilih posisi berada di kiri (Left), ukuran asli (Original size) atau dapat disesuaikan dengan kebutuhan kita.

6. Selain dari menu Upload kita juga dapat menyisipkan gambar ke blog dengan menu Insert Image 
Available online at https://jurnal.stmikroyal.ac.id/index.php/jurdimas

menggunakan pilihan menu-menu didalamnya berupa menu From This Blog (sisipkan gambar dari gambar yang ada di blog/sudah diupload), From Picasa Web Albums (sisipkan gambar dari album picasa web), From your phone (dari telpon), From your webcam (dari webcam kita) dan From Url (dari link url gambar pada web lain), atau layanan pihak ketiga seperti Flickr.

7. Klik tombol Pratinjau untuk melihat hasil preview dari postingan blog kita. Atau tombol Publikasikan untuk menerapkan hasilnya langsung ke blog.

Menambah Tautan Link Pada Posting Blog

1. Link merupakan tautan yang dapat berupa kata, kalimat, barisan kalimat, atau juga sebuah gambar/foto yang jika di klik maka akan membuka halaman dari alamat suatu website/blog lain atau website/blog yang sama. Kita buat linknya dengan masuk ke account blogger kita di alamat https://www.blogger.com. Setelah masuk ke Blogger, klik ikon segitiga terbalik (Opsi lainnya), kemudian pilih opsi Pos untuk menuju halaman posting kita sebelumnya.

2. Kita dapat membuat posting baru dengan tombol Entri baru atau kita dapat mengedit draf pada tutorial sebelumnya, klik Edit

3. Saatnya kita membuat link di blog yang dapat dilakukan dengan dua cara, cara pertama dengan klik menu "Compose" atau cara kedua dengan klik menu "HTML". Baiklah kita jelaskan cara yang pertama dulu, klik menu Compose. Selanjutnya ketik sebuah kata dan seleksi/blok kata tersebut untuk kita buat linknya, dalam tutorial ini dicontohkan dengan men- seleksi kata IT_HouseMedia dengan mouse, atau kita dapat sesuaikan dengan kata, kalimat, barisan kalimat, atau juga sebuah gambar/foto yang ingin kita buat linknya. Selanjutnya klik menu Link.

4. Maka akan tampil jendela Edit Link. Maka pada kotak input Text to display akan tertulis kata yang di seleksi secara otomatis (IT_HouseMedia) yang akan dijadikan sebuah link ke http://ithousemedia.blogspot.com pada kotak Web address (sesuaikan dengan link alamat website yang ingin dituju). Beri tanda ceklis Open this link in a new window agar membuka link pada jendela atau tab baru saat link tersebut di klik. Sedangkan opsi pilihan Email address digunakan untuk membuat link yang tujuannya untuk mengirim e-mail pada email yang diketik, contoh ke email ithousemedia@gmail.com pada kata IT_HouseMedia yang diseleksi sebelumnya dan Add 'rel=nofollow' attribut adalah untuk menambahkan atribut atau informasi tambahan untuk link tersebut yang berfungsi memberikan keterangan/informasi kepada mesin pencari seperti google untuk tidak melacak link tersebut di mesin pencariannya. Klik OK untuk melanjut.

Menambah Video Pada Isi Blog

1. Buka posting editor blog kita dan letakkan kursor mouse di posisi yang ingin disisipkan video pada posting editor. Kemudian klik ikon Insert a video pada toolbar Pos Editor.

2. Maka sebuah jendela akan muncul yang meminta kita untuk menyisipkan video ke posting blog dengan berbagai pilihan yang tersedia (Upload, From You Tube, My You Tube videos, From your phone 
Available online at https://jurnal.stmikroyal.ac.id/index.php/jurdimas

dan From your webcam). Kita akan jelaskan cara menyisipkan video dengan cara menggunakan menu, klik Upload.

3. Seret/drag video yang diinginkan ke dalam kotak bertuliskan Seret video ke sini atau klik tombol biru Pilih video untuk diunggah.

4. Cari lokasi file video (berupa AVI, MPEG, QuickTime, Real dan Windows Media yang harus kurang dari 100MB) pada drive komputer kita yang ingin disisipkan, selanjutnya klik Open untuk membuka video.

5. selanjutnya proses mengunggah video, maka proses upload video sedang berjalan yang ditunjukkan pada pesan status bar browser Tunggulah sampai $100 \%$ selesai, mengenai waktu uploadnya tergantung pada ukuran video yang diupload. Ketika selesai sampai $100 \%$, video akan muncul dalam post editor kita.

6. Untuk melihat hasil sementara sebelum dipublikasikan, klik pratinjau maka video akan ditampilkan pada halaman blog kita.

Upload video dari You Tube (Upload from You tube)

1. Setelah menu Insert a video di klik, pilih menu From You Tube, kemudian ketikkan kata kunci pada kotak pencarian you tube misalnya kata blogspot untuk menampilkan video yang berhubungan dengan kata tersebut. Enter atau klik tanda ikon kaca pembesar maka kumpulan video akan ditampilkan. berikutnya pilih video yang ingin disisipkan dan klik tombol Pilih.

2. Maka video dari you tube yang kita pilih disisipkan pada post editor kita.

3. Klik pratinjau untuk melihat hasil sementara pada page blog kita.
Upload video dari You Tube dengan kode HTML

1. Dari tampilan menu Compose ubah menjadi ke Post editor HTML, Klik menu HTML, selanjutnya buka halaman you tube di https://www.youtube.com. Cari video yang ingin disisipkan misalnya vidoe dengan keyword/kata kunci mario teguh golden ways.

2. Maka akan ditampilkan kumpulan video, klik salah satu pada link video tersebut.

3. Klik menu Bagikan/share dibawah video

4. Maka akan ditampilkan beberapa menu, pilih menu Sematkan kemudian blok dan copy (CTRL+C) kode di kotak seperti tampilan gambar berikut.

5. Untuk mencopy klik kanan pada kode yang telah di blok kemudin pilih menu salin atau dengan menekan tombol CTRL dan $\mathrm{C}$ bersamaan.

6. Beralih ke jendela post editor blog kita dan pastekan (CTRL+V) kode tersebut, sehingga tampak seperti pada gambar berikut

7. Klik menu Compose lagi, untuk melihat hasil video yang disisipkan pada post editor blog kita.

8. Klik pratinjau untuk melihat hasil sementara, simpan untuk menyimpan sebagai draft atau publikasikan untuk mempublikasikan video tersebut pada blog kita.

\section{B. Documentasi Acara}

Berikut foto-foto dokumentasi acara kegiatan Pengabdian Kepada Masyarakat pada SMA Negeri 2 Kisaran :

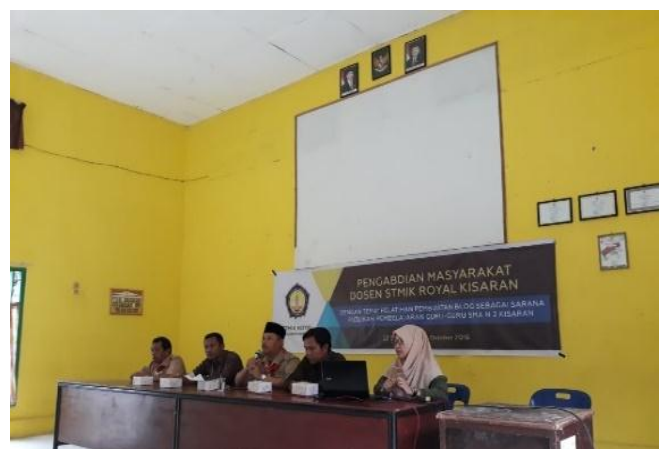


Gambar 4. Foto Bersama Peserta Kegiatan PKM
Gambar 1. Pembukaan Acara Oleh Kepala Sekolah

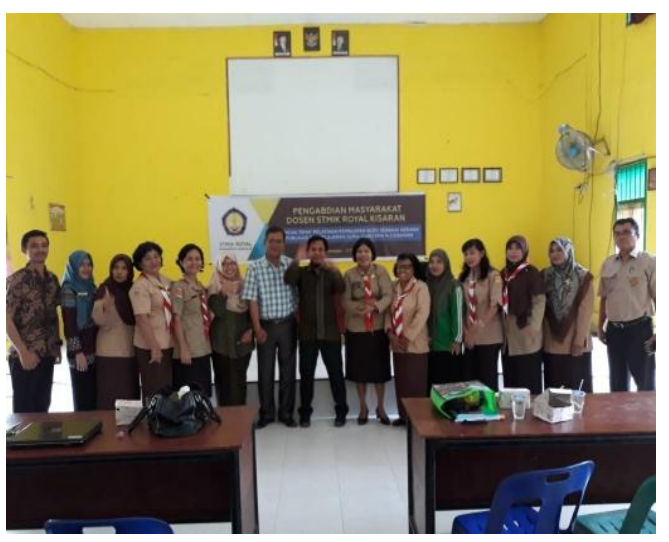

Gambar 2. Penyampaian Materi Oleh Nasumber

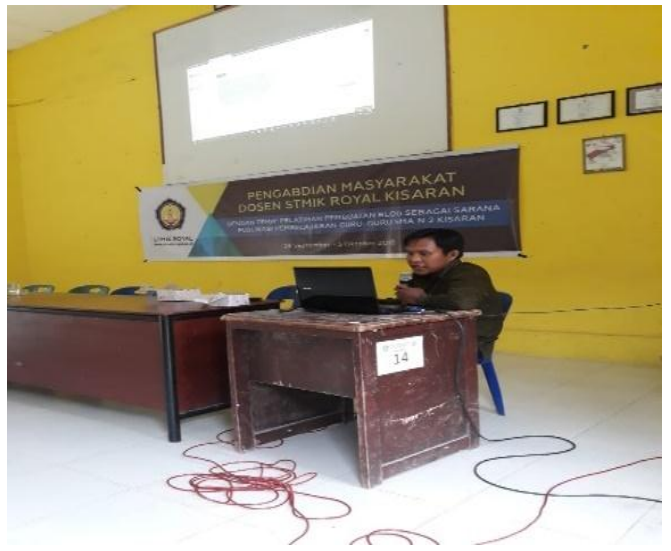

Gambar 3. Praktek Pembuatan Blog dan Publikasi Pembelajaran

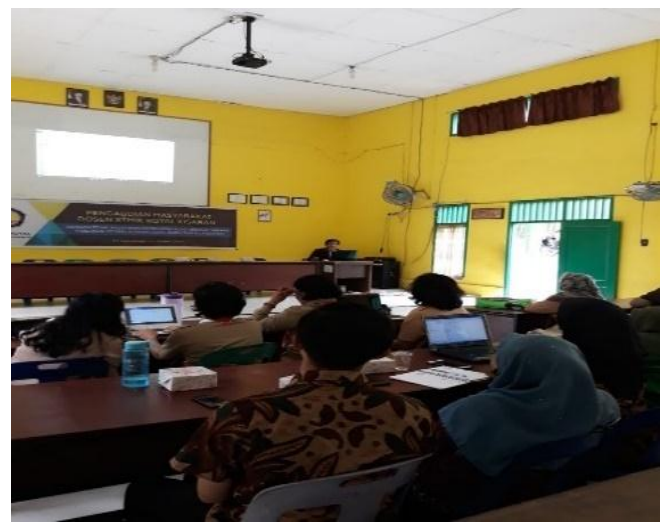

\section{SIMPULAN}

Berdasarkan kegiatan pengabdian kepada masyarakat yang dilakukan pada SMA Negeri 2 Kisaran dapat disimpulkan bahwa :

1. Kegiatan pengabdian kepada masyarakat yang dilakukan oleh Tim kegiatan (dosen dan mahasiswa STMIK Royal Kisaran) tepat pada sasaran karena pengetahuan yang diberikan kepada peserta dapat dimanfaatkan untuk mempublikasikan pembelajaran guru-guru SMA Negeri 2 Kisaran.

2. Target kegiatan pengabdian telah berhasil dilaksanakan ditunjukkan dengan setiap peserta kegiatan telah memiliki account blog (blogger) dan mampu melakukan manajemen dashboard blogger masing-masing berdasarkan bidang studi yang diajarkan.

3. Pihak sekolah dan jajarannya memiliki koordinasi dan kerjasama yang baik dengan tim dan setiap peserta memiliki antusias yang tinggi dalam mengikuti kegiatan pelatihan yang diberikan.

\section{UCAPAN TERIMA KASIH}

Ucapan terima kasih kami sampaikan kepada Ketua Yayasan Royal Teladan Kisaran bapak Anda Putra Lubis, SE., M.MA yang telah mendanai 
Available online at https://jurnal.stmikroyal.ac.id/index.php/jurdimas

kegiatan ini. Kepala Sekolah SMA Negeri 2 Kisaran bapak Syahruddin Lubis, S.Pd, MM beserta jajarannya yang telah membantu dan menyediakan fasilitas selama kegiatan berlangsung serta Tim pengabdian kepada masyarakat yang telah bekerjasama dengan baik, sehingga kegiatan dapat berjalan lancar dan sukses.

DAFTAR PUSTAKA
Creativity, J. 2015. "Buku Master Blogger”, Jakarta, PT Elex Media Komputindo.

Krisianto, A. 2015. "Jago Blogspot”, Jakarta, PT Elex Media Komputindo.

Madcoms, 2015. "Bikin Sendiri Blog dengan Blogger untuk Pemula", Yogyakarta, Andi Publisher. 